\title{
Comparative and QoS PERFormance ANALYSIS of Terrestrial-Aerial Platforms-Satellites SYSTEMS FOR TEMPORARY EVENTS
}

\author{
Faris. A. Almalki \\ Department of Computer Engineering, College of Computers and Information Technology \\ Taif University, Kingdom of Saudi Arabia
}

\begin{abstract}
Wireless communications, nowadays, becomes a vital element of people's daily life. Providing global connectivity in future communication systems via the heterogeneous network opens up many research topics to investigate potentialities, enabling technologies, and challenges from the perspective of the integrated wireless systems. This paper aims to drive a comprehensive and comparative study on terrestrial-aerial platforms- satellite wireless communications systems, includes their characteristics and unravelling challenges. The comparison focuses on issues that reportedly can evaluate any wireless systems for temporary events. These issues are altitude and coverage, Radio Frequency (RF) propagation, interference, handover, power supply constraints, deployment and maintenance challenges, reliability on special events or disaster relief, cost-effectiveness and environmental impact. Last, Quality of service $(Q \circ S)$ performance is analysed for the four wireless communication systems from the temporary events perspective using the OPNET Modeller simulation tool. Results infer that space-based wireless systems outperform terrestrial ones.
\end{abstract}

\section{KEYWORDS}

Terrestial; Aerial Platforms; Satellites; QoS Performance; Temporary Events

\section{INTRODUCTION}

Wireless communications enable information to be transmitted over a distance between two points or more, such as radio communication, without the need of cables, wires, or any other electrical conductors. Wireless systems and services have been evolving swiftly as one of the most essential means of everyday communication. Commonly, wireless communication systems can be divided into three popular types: broadcasting, satellite and cellular services [1-2]. The wireless communication introduces several advantages over wired communications, not only in terms of mobility within a coverage area but also in terms of scalability; there is no need for (re)wiring to (re)connect and no service interruption to the rest of the system. Besides the initial costs, the cost of running and maintaining a wireless communication service is much less than the wired one. Moreover, difficult terrain or long earthly distance no longer poses an issue as wireless communications can be taken to remote areas, which in turn may support the provision of applications and services such as e-educational, meteorological and e-commerce. Bell of Canada's recent advice is to optimize wireless connectivity resources for greater efficiency and productivity [3-5]. Further, in man-made or natural disaster scenarios, wireless communication systems have the further merit that much less of the infrastructure is vulnerable to physical damage. Disaster Management and Emergency Response have widely adopted the use of wireless sensor networks for numerous applications, such as gas leakage, water level monitoring, and air pollution monitoring, all of which can help towards public safety, which in turn may lead to an 
environment which is more stable and secure. Therefore, these advantages of mobility, expandability, affordability, connectivity, productivity, and surveillance and disaster management for public safety and security are catalysts in user desirability for more wireless technology. However, it is widely accepted that certain aspects of wired communications systems are far superior to the wireless equivalent: speed and security [6-7].

Wireless communication services can be enabled either by terrestrial and/or space-based systems includes satellites, aerial platforms; which might be High Altitude Platforms (HAPs), or Low Altitude Platforms (LAPs). Although these systems provide services with a good level of data rates, re-configurable provision with various dynamic coverage demands. However, the deployment of these enabling technologies has led to a huge rise in the demand for mobile communications, partly due to the exponential growth in multimedia traffic, and partly due to the emergence of a new types of technology such as the Internet of Things (IoT), or Big Data which in turn needs rapid developments in these wireless communication means. Moreover of the objectives that emphasise the idea of conducting such a comprehensive work on these wireless communication technologies is shedding the light on a heterogeneous wireless topology [6-8]. To note, some references in the literature like [72] introduces the Medium Altitude platform (MAP) with its own characteristics. However, nothing to get excited about the names as the major focus in the literature was on the altitudes; Where it is classified as: first: below Stratosphere layer (few hundred meters to $10 \mathrm{~km}$ ), which represents LAPs and include MAPs as it states in [73];second: at the Stratosphere layer (17-20km), which exclusively represents HAPs. These altitudes show the best conditions (e.g. low wind speed, reasonable temperature, fewer flight paths of both civil and military), which all help for platform stability.

The heterogeneous wireless topology can be achieved by deploying a multilayer approach that integrates a terrestrial system with a space system that includes LAP, HAPs, and satellites. This will provide seamless services over heterogeneous networks to offer a high QoS for global connectivity. This architecture consists of various layers that can provide different applications and services. Each of the architecture's layers has different hardware and software capabilities, as well as different frequency ranges. To achieve the integration idea, it is necessary to take into consideration the available bandwidth, coverage, frequency ranges, uplink and downlink connectivity, and interfaces between the terrestrial aerial platforms satellite systems. Communication between the integrated system can either be optical or RF. The integrated system includes aerial platforms network that is connected by inter-platform links, some ground stations linked by platforms using both backhaul links, as well as hosting gateways to external networks, intermediate nodes connected to the local wired or wireless system and platforms system, and satellite links using backhaul links towards platforms and ground stations [7-9].

Considering an intensive study on four terrestrial, aerial platforms (HAP/LAP), and satellite wireless communications systems are scarcely reported in the literature and where it focuses on issues that reportedly can evaluate any wireless systems let alone taking into consideration QoS parameters as part of the comparison. The motivation in this paper is to introduce a comparative study on these wireless systems from two perspectives. First, drive a comprehensive study in the selected systems includes their characteristics and unravelling research issues. Second, consider QoS performance analysis for the four wireless communication systems from short-term largescale events perspective using the OPNET simulation tool. The rest of this paper organized as a brief illustration of the terrestrial in section 2. In section 3 and 4 cover aerial platforms (HAP and LAP), and satellite systems, respectively. Followed by section 5 general discussion on open research issues associated with the four wireless systems and then drive a comprehensive comparison between them. Section 6 shows the proposed architecture and QoS performance analysis simulations and discussions of the selected wireless systems and finally, the conclusion in section 7 . 


\section{WiRELESS COMMUNICATIONS: TERRESTRIAL SYSTEMS}

The cellular terrestrial system is a wireless network which divides the geographical area into many cells. Terrestrial links are generally used to provide services in a complex propagation environment [2]. Each cell includes at least a single Base Station (BS) with a frequency that is different from that of its neighbour cells, to avoid interference, as well as offering the best bandwidth within each cell. Antennas within cellular systems usually tend to be Omni-directional or recently smart antenna types, to cover as many reigns as possible. The cellular architecture usually divides metropolitan and countryside zones into parts in accordance with specific wireless service rules. Thus, the performance of the cellular system can be measured by the number of deployment parameters associated with the cell, such as the cell's size and shape, cell-splitting, as well as the number of users in a cell. This includes the efficiency of frequency reuse, and the handover process [1-3].A study shows that by 2020 the total connected devices that require wireless service will possibly reach 50 billion [9]. In turn, mobile network providers will install more BSs to develop their network's infrastructure to accommodate more users. Deploying a huge number of BSs to serve mobile users across the world will lead to certain issues that evaluate the network performance of cellular mobile communication systems quite challenging [10]. This section discusses the most common issues that are associated with cellular mobile communication systems: coverage area, data rate and capacity, path loss and shadowing, power consumption, handover process, surveillance and disaster management, and supporting short-term-events.

Extending wireless coverage range to meet the rapid demand for wireless service from subscribers in different geographical locations underpins wireless communications. A terrestrial network's coverage range may range upto few tens of miles depending on area morphology, transmission power, propagation conditions, traffic distribution, and of course a cell's layout [2, $11,12]$. Moreover, the coverage area does not only refer to the outdoor environment but also, indoors. Several approaches have been developed to improve the wireless communication performance such as Millimetre-Wave [9-11], Multihop Cellular Networks by using Mobile Relays (MCR-MR) [13], Multiple Input Multiple Output (MIMO) or "spatial multiplexing" [1215], device to device (D2D) [14-18], Distributed Antenna Systems (DAS) [4, 19], Cognitive Radio (CR) [11, 17], Small cells (e.g. Femtocells) [14, 21,22], and cooperative relaying technology [17, 23]. Yet, delays, security, complexity, immature technology, interference management, and power consumption are the main challenges that face these cut-edge technologies.

Cellular network systems are facing a problem of scalability with wireless broadband and increased usage with applications and services. According to a CISCO study, the monthly global mobile data traffic is estimated to grow at around 24.3 Exabytes by 2019, which is five times the current traffic[14]. Therefore, the Third Generation Partnership Project (3GPP) has introduced Long-Term Evolution (LTE) with MIMO and Long Term Evolution-Advanced (LTE-A) technologies as a response to enhance capacity, coverage, and provide high data rates [24]. Moreover, fifth-generation (5G) is widely anticipated to offer a data rate that could reach up to 10 GB/s [14]. Furthermore, its heterogeneity infrastructure enables the inclusion of micro, pico, and femtocells, as well as distributed antennas and relay nodes [24]. However, cell selection and reselection, load balancing, cyclic delay diversity, handover management, and data rate increases lead to increased power consumption; besides the immaturity of $5 \mathrm{G}$ technologies are still open challenges.

The handover or handoff $(\mathrm{HO})$ process makes roaming much more efficient which in turn enables mobility that underpins wireless communications especially if it is achieved without either service interruption or user awareness [2, 4]. There are several techniques have been proposed that appear improvements with the HO process as suggested by the literature, for instance, MCR-MR in [13]. 
Timing upper bound, and Margin lower bound in [25], a pre-HO algorithm in [17, 26], and small cell deployment in $[22,27,28]$. Whilst various challenges remain; these include lack of support for High-Speed Packet Access (HSPA), Ping-Pong effect, complex estimation process, high probability for data loss and outage, and inter-cell interference. Topping these are delays due to the processed of $\mathrm{HO}$ authentication and pre-HO, which in turn lead, separately, to a decrease in QoS [13, 27-30].A major concern associated with wireless communication systems is signal propagation effects. Signals are prone to a multitude of propagation problems, such as path loss, shadowing, multipath, non-line of sight (LoS) problems (e.g. reflection, diffraction, refraction, scattering). These usually lead to attenuation, long-term and short-term fading, which indeed decrees the signal's QoS level $[2,9]$. Noticeable improvement in network performance can be drawn from Several approaches that have been proposed (e.g. Suzuki fading model, G- and Kdistributions) to reduce shadowing, and multipath issues [31-33]. Otherwise, several disadvantages come to the fore, for instance, delay due to routing and relay-node selection. All considerations exclude an increase in BS complexity and cost.

The number of BSs that have been deployed around the world is predicted to be 11.2 million by 2020, with almost 2.4 times in 2013 [10]. Many researchers indicate that BSs consume approximately $80 \%$ of a cellular system's total energy [10, 11]. Thus, network operators, government authorities, and many researchers are motivated to explore more advanced techniques to achieve energy efficiency for both financial or environmental reasons. The results of many are optimistic techniques suggest that energy consumption may be reduced by up to $70 \%$, and carbon dioxide emission will be reduced by an average of 50\% [10, 34, 35]. For example, Hybrid Traffic Prediction in [10], combined ad hoc and cellular technologies (e.g. MCR-MR) in [13], a multi-tier network with a macrocell overlaid by relays (e.g. femtocells, and D2D) in [13, 36], Cell-onDemand, Coop MIMO, Relaying, Radio Resource Management (RRM), and Sleeping mode in $[14,35]$. However, some of these approaches have yield limitations with the routing process, complexity, co-channel interference increased delay, as well as security $[13,36]$. Thus, great interest from most telecommunications sectors for green innovation uses a mixture of solar, wind, and fuel cell energy, which could solve some of the power consumption issues, and also providing energy sources to BSs to isolated areas or difficult geographical terrains.

Whilst terrestrial networks support an enormity of wireless services, they are, nevertheless, extremely vulnerable to man-made and natural disasters [2,6]. According to the ITU when a disaster occurs, the terrestrial telecommunications infrastructure fails are usually due to the physical destruction of a network, disruption in the supporting network infrastructure and Network Congestion [37]. The reliability of telecommunication systems during emergency crises made the difference between life and death in respect of the response of the local authorities, where it is essential to have a large-scale and robust communication network for broadcasting instructions to people, seeking rescue aid, as well as providing inter-departmental communications. Table 1 below summarises the main challenges with terrestrial communications, as have been discussed above.

Table 1 Challenges with terrestrial communications

\begin{tabular}{|c|l|}
\hline Topic & \multicolumn{1}{c|}{ Challenges } \\
\hline \multirow{4}{*}{ Energy } & High power consumption in BSs \\
\cline { 2 - 2 } & Energy provision in remote areas \\
\cline { 2 - 2 } & $\begin{array}{l}\text { Partially environmentally unfriendly, due to high Carbon dioxide } \\
\text { emission for energy production }\end{array}$ \\
\hline \multirow{2}{*}{$\begin{array}{l}\text { Coverage } \\
\text { Footprint }\end{array}$} & $\begin{array}{l}\text { Interference management due to, e.g. multi-tier network } \\
\text { Limited coverage area, which depends on the certain issues, e.g. layout } \\
\text { of coverage area, transmission power, propagation conditions }\end{array}$ \\
\hline
\end{tabular}




\begin{tabular}{|c|l|}
\hline \multirow{2}{*}{$\begin{array}{c}\text { Propagation } \\
\text { model }\end{array}$} & Handover complexity due to, e.g. small cells \\
\cline { 2 - 3 } QoS & $\begin{array}{l}\text { LOS is mountain or metropolitan areas } \\
\text { coverage resulting in shadowing and multipath }\end{array}$ \\
\hline \multirow{2}{*}{ Reliability } & QoS levels in coverage area affected by signal attenuation \\
\hline & $\begin{array}{l}\text { Higher data volume due to wide range of innovative applications and } \\
\text { services }\end{array}$ \\
\cline { 2 - 3 } & $\begin{array}{l}\text { Complexity of essential staged deployment especially in urban areas } \\
\text { communications are vulnerable to failure }\end{array}$ \\
\hline Cost & $\begin{array}{l}\text { High cost infrastructure to provide wireless services for short-term } \\
\text { large-scale events }\end{array}$ \\
\hline
\end{tabular}

Hence, outer space communication systems, such as satellites, LAP, and HAPs have several advantages over existing terrestrial cellular networks, where authors in [6] list several examples of space communication systems had successfully established ad-hoc networks for disaster relief. This is largely due to outer space communication systems covering a wide area, offering deployment flexibility, forecasting disaster evolution, providing last-mile connectivity, and affording terminal mobility [38, 39]. Although the number of BSs across the world is anticipated to rise to $11 \mathrm{~m}$ by 2020 [10], a BBC report in 2014 claims that many of the world's poorest people do not have the means or technology to log on into a network, with just $31 \%$ of people in the developing world using the internet, compared to $77 \%$ in the developed countries [40]. Thus, providing wireless communications services in isolated areas with harsh terrains could be economically infeasible or physically impossible even with such a huge number of BSs. There could be several reasons for this, including the supply of power to towers, LoS with other towers, operation, and maintenance, cost and number of users. Large-scale short-term events taking place regularly often meet the cost of temporary wireless communication infrastructure. However, outer space communication systems can serve as the solution for an isolated area with difficult terrains, or instead of a temporary wireless communication infrastructure [38-40].

\section{Wireless Communications: AERIAl SySTEMS}

The Aerial wireless communication system includes both LAPs and HAPs. In 1997 HAP technology was recognized as stratospheric layer repeaters, according to the WRC No. S1.66A, placed at an altitude ranging from 17 to $50 \mathrm{~km}$ above the ground. Such platforms are of flexible size since they are usually helium-filled and solar-powered airships and can be used for various applications and services such as telecommunications, broadcasting, environmental measurements, surveillance, emergency services, localization and navigation, and e-services. The ITU has described HAPs as "representing a new and long-anticipated technology that can revolution of the telecommunication industry". Further, a HAP's position in the sky could take advantage of the strengths of terrestrial and satellite communication systems, whilst avoiding some of their weaknesses. Depending on the minimum elevation angle, HAPs offer coverage of a wide service area of around $400 \mathrm{~km}$ with a semi-permanent, high data rate and high capacitydensity communications services. HAPs are increasingly seen as an innovative solution to the last-mile problem [39-43].

On the other hand, the LAPs system has gained significant attention as a key factor for providing dynamic and scalable networks, using various on-board communication payloads [44]. LAPs can cover fairly wide areas with a radius of $30 \mathrm{~km}$ or more, depending on configuration, and communication payloads. Indeed, by increasing altitude and/or transmit power of LAPs system 
that leads subsequently to increase the coverage area as well as improve received signal strength [45]. Also, such a system can sincerely achieve bandwidth demands for first responders. LAPs system can be typically categorized into two types. The first type is an unmanned airship that flies in the Troposphere layer up to $5 \mathrm{~km} \mathrm{[6].} \mathrm{The} \mathrm{second} \mathrm{type} \mathrm{is} \mathrm{the} \mathrm{tethered} \mathrm{platforms,} \mathrm{which} \mathrm{they} \mathrm{can}$ classically function at altitudes of up to $5 \mathrm{~km}$; using ultra-strong lightweight tethers, to provide stationary, power and communications required. Moreover, these kinds of aerostats have been utilized for many years to operate some functions, such as communications nodes, monitoring and surveillance, aerial imaging, and security applications $[1,5,6]$. The aerial platform's position in the sky could provide many of the satellite advantages, but without the distance penalty.

Furthermore, aerial platforms receivers may experience a better signal quality, as the system offers LoS communications, hence, less propagation delay about satellite systems. Deploying a network of aerial platforms in the sky with inter-platform links (IPLs) will swiftly bridge communication gaps through a soft infrastructure, a fast start-up time, gradual growing, ondemand capacity assignment, with low capital investment, as well as low ongoing operating costs $[39,42]$. The aerial platforms represent a viable alternative infrastructure for the long-term provision of broadband access to stationary or mobile users. Also, they are particularly wellsuited for temporary provision of basic or additional capacity requirements, due to their rapid deployment and control of their flight path. With rapidly changing communication demands, they provide network flexibility and reconfigurability. In consideration, aerial platforms are suited for serving remote regions with low user density, short-term large-scale events, and establishment of ad hoc networks for disaster relief, and also for providing telecommunication services. They offer several obvious advantages over terrestrial or satellite systems, such as larger coverage area, higher capacity, lower cost of manufacturing, launch, and maintenance [39, 42]. There have been several projects around the globe from Europe (e.g. EU HeliNet, European COST Action 297, British StratSat, ABSOLUTE), North America (e.g. Canadian HALE Platform, Sky stations, Lockheed Martin), Asia (e.g. Japanese Skynet, Korean ETRI), and international cooperation across many countries (e.g. CAPANINA, Google's Loon) [45,46].

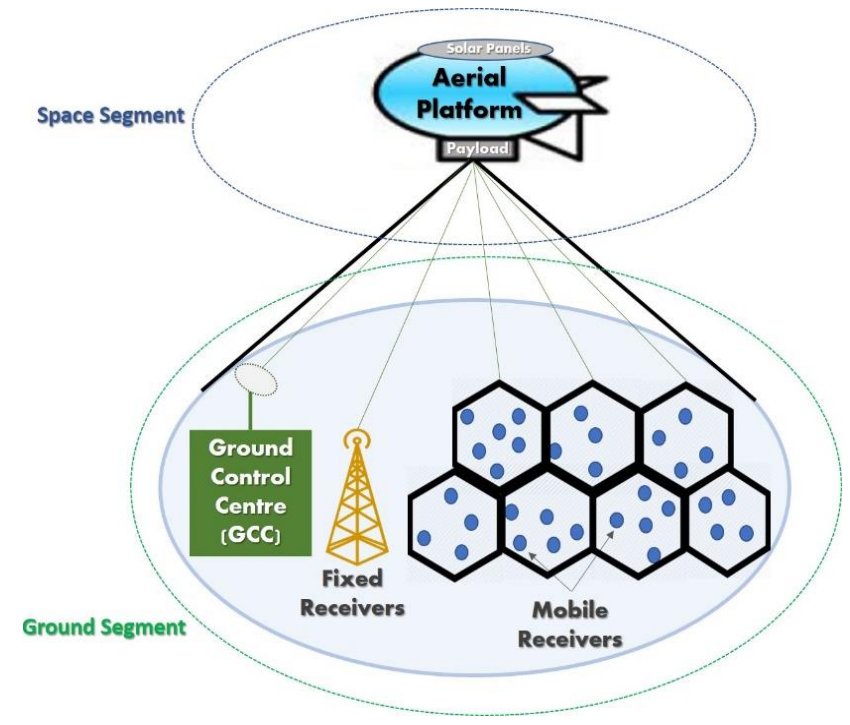

Fig. 1: The aerial Platform system structure

The aerial platform system requires two main segments: space and a ground segment as seen in Fig. 1. The space segment consists of at least one unmanned aeronautical platform that carries a communication payload, integrated solar arrays and fuel cells, and a station-keeping system. The ground segment has missions of a Ground Control Centre (GCC) is to control an aerial platform's 
functionality and flight tasks, the link between platform and users, the backhaul link to other terrestrial or satellite networks, and a large number of roaming subscriber access terminals. The GCC also controls the number and directions of the generated beams to form the ground cells via antennas $[3,7,8]$.Various wireless network topologies of the aerial platforms namely standalone, integrated terrestrial- aerial platforms, and integrated terrestrial- aerial platforms -satellite. The standalone topology resembles a star configuration and acts as the main hub. Users within such a topology can communicate with each other, as well as with other users in other networks using gateways on the ground. Using this topology depends on the QoS requirements, type of application, and payload, both weight and power consumption, which has its advantages and applications. On the other hand, the integration between aerial platforms and terrestrial systems has many advantages, ranging from an increase to capacity demand, to more cellular coverage area in fourth-generation $(4 \mathrm{G})$ and other networks, to endowing terrestrial networks with wireless communication services. Again, using this topology depends on the purpose of the applications provided, where some challenges that normally need to be considered include handover, interference, resource allocation, cell structures, and dynamic channel assignment. Some of these issues are found common in both HAP and LAP, while others are in one type. The biggest challenge is station keeping or platform stability due to weather systems results in-service degradation and in-turn requires increased power consumption to rectify [7-9].

Identifying the optimal altitude and achieving a maximum coverage area is considered in [47-48], where the authors report a strong correlation between the optimum LAP altitude and other parameters such as environmental, modulation scheme, path loss, and coverage range. Further, the propagation models for LAPs technology reported in the literature are based either on Air-ToGround (ATG) [47-51] or empirical propagation like Hata in [8, 7, 45]. The ATG models show an improvement in cell capacity and downlink coverage. However, they also show that environmental properties, antenna types can affect considerably the LAP capacity. One great advantage of ATG is that urban NLoS can be modeled without any concerns over building shapes, heights, and distribution according to Rayleigh's probability density function. Recommendations have been raised in [47, 48] about the significance of studying and investigating various LAP propagation models that can identify the optimum altitude and achieve maximum coverage area in different rural or urban environments. To note, as far as our concern free space propagation model is the only one has been considered in HAPs due to the distance $(17-20 \mathrm{~km})$. Frequency band harmonization is essential to avoid harmful interference between the terrestrial base stations and (temporary) base stations on-board the LAPs. Consideration is given to the antenna type since omni-directional antennas consume more energy thus limiting frequency reuse, increasing interference and reducing capacity. For instance, in [51, 52] it is confirmed that more coverage and less interference could be achieved through directing of both the balloon and the antenna beam. It has been suggested to consider the use of either smart or multiple antenna technology to improve performance. Moreover, because of the Alamouti's scheme MIMO antenna technology is very similar to smart antenna technology and is one of the most efficient leading innovations in wireless systems for maximum capacity, improved QoS and coverage extension range [52, 53, 74]. The effect of MIMO antennas on near-space solar-powered platforms performance and capacity is discussed in [54-56], where it is argued that the antenna gain has to be optimized, otherwise, user ends will experience weak radio across a distance of many miles. Furthermore, anisotropic antenna type is considered in [47], whereas in [48] an electronically switched beam antenna is deployed that is capable of steering the RF power to and from a certain direction, which can mitigate interference on LAP coverage zones. In [48] a smart antenna is suggested to enhance results. An open issue in wireless communication systems is signal propagation effects (e.g. path loss, shadowing, multipath, reflection, or scattering), still without any complete solving, due to nature of how the RF propagate. Some of these issues can be reduced using a smart antenna or MIMO technology or proper RF modeling in some specific areas. Yet, tailoring and adaptation of channel assignment and resource allocation are affected by 
applications with QoS requirements such as multimedia. The ITU's International Mobile Telecommunications-Advanced (IMT-Advanced) standard for 4G offers access to various telecommunication services and supports mobile applications for heterogeneous wireless environments that offer high data rates to user and service requirements. As such, it can support the performance and high QoS requirements for multimedia applications. The ITU has considered two technologies that met the criteria of the standard: LTE-A, and IEEE $802.16 \mathrm{~m}-2011$ Worldwide Interoperability for Microwave Access (WiMAX 2) [57-59]. Both WiMAX and LTE assume an all-IP network approach, use Orthogonal Frequency-Division Multiple Access (OFDMA) in the downlink (DL), support Time-Division Duplex (TDD) and Frequency-Division Duplex (FDD), support different bandwidths, use smart antenna and MIMO technology, provide QoS support, use similar modulation techniques such as Quadrature Phase Shift Keying (QPSK) and Quadrature amplitude modulation (QAM) 16QAM, 64QAM in both the DL and uplink (UL). However, they are quite different in their evolution, frequency bands, industry support, and deployment models. The peak data rate in LTE advance (release 12 and 13) is $1 \mathrm{Gbps}$ in DL, and $500 \mathrm{Mbps}$ in UL, with a coverage range of up to $100 \mathrm{~km}$. WiMAX release 2 can offer peak data rates of $350 \mathrm{Mbps}$ in the DL, and $200 \mathrm{Mbps}$ in the UL with a coverage range of up to 50km. LTE technology seems better than WiMAX in terms of data rate and coverage range and, as a consequence, it has been deployed more widely than WiMAX.

An aerial platform technology, whether HAP or LAP, both WiMAX and LTE have performed well and suggested as good candidates for better coverage whether in LoS or NLoS, increased capacity and less interference [59-63]. However, opinions and decisions vary. For instance, ABSOLUTE is one of the most important LAP project worldwide that deploy LTE in its specifications $[50,60]$. [62, 64] deploy WiMAX technology in their designs for costeffectiveness. In [63] the authors emphasize the advantages of deploying WiMAX over LTE-A in supporting military operations in disaster relief environments where users' requirements change rapidly. On the other hand, WiFi has its own advantages and applications but it suffers from interference, as transmission power levels affect coverage in contrast to a tethered balloon where power can be supplied via a cable $[47,59,64]$. Rain attenuation and scattering affect a HAP's high frequencies bands (e.g. $47 / 48 \mathrm{GHz}$ and $28 \mathrm{GHz}$ ). While in LAPs. Table 2 below summarises the main challenges with aerial platform communications, as have been discussed above.

Table 2 Challenges with aerial platform communications

\begin{tabular}{|c|l|}
\hline Topic & \multicolumn{1}{|c|}{ Challenges } \\
\hline \multirow{2}{*}{ Energy } & $\begin{array}{l}\text { Platform stability due to weather systems results in QoS degradation, which in } \\
\text { turn requires increased power consumption to rectify }\end{array}$ \\
\cline { 2 - 3 } Coverage & Minimize weight of solar panels \\
\hline Footprint & Trade-off between low elevation angles, path loss, coverage \\
\hline $\begin{array}{c}\text { Propagatio } \\
\text { n model }\end{array}$ & Suffers from the lack of investigating various propagation models \\
\hline \multirow{2}{*}{ QoS } & $\begin{array}{l}\text { Lack of legalization for high frequencies bands (e.g. 47/48 GHz), yet } \\
\text { attenuation and scattering affects performance }\end{array}$ \\
\hline \multirow{2}{*}{ Reliability } & $\begin{array}{l}\text { Platform stability due to wind is the main challenge especially for lower } \\
\text { altitudes }\end{array}$ \\
\cline { 2 - 3 } & Considering optical inter-platform links is an open challenge due to stability \\
\hline \multirow{2}{*}{ Cost } & $\begin{array}{l}\text { Deep business analysis is required to understand the market potential for some } \\
\text { cases }\end{array}$ \\
\hline
\end{tabular}




\section{Wireless Communications: SATEllite SystemS}

Satellite communication systems are radio relay stations that orbit at different altitudes in space. The high altitude affords them a very large coverage area, thus making them capable of providing a variety of different communication applications and services, such as TV and radio broadcasting, mobile communications, navigation, military services, disaster relief management, and weather forecasting. Users who are separated geographically may get the advantage of using a satellite system, which becomes a star node to them. The alternative, i.e. terrestrial communication systems, has an infrastructure complexity as a result of needing one or more connection to BSs, antennas, switches, location registers and much more. A basic satellite system structure comprises of space and ground segments. One space segment consists of a single platform with its payload and receiving and transmitting antennas to support transmission. Satellites may be connected by either optical or radio links. On the ground segment there are several, types of stations such as gateways and terminals for broadcast service, TT\&C which controls a satellite's functions and conditions from the ground, as well as stationary and mobile communications [1, 3, 38, 65].

Satellite communications services can be broadly classified into three classes according to the ITU, which is: Fixed Satellite Services (FSS), Broadcast Satellite Services (BSS), and Mobile Satellite Services (MSS). The FSS provides a radio-communication service between stationary earth stations and one or more satellites orbiting earth. This service may also include feeder links for other space radio communication services. The BSS provides a direct individual and community radio-communication service between space stations and the general public that have a ground satellite antenna. MSS provides a radio-communication service either between mobile earth stations and one or more satellites orbiting earth or between the satellites or mobile earth stations using this service. Satellites are categorized according to their orbital altitude in relation to the Van Allen ionosphere radiation belts. A belt may affect a satellite's lifetime due to radiation levels, which in turn may influence the choice of orbital altitude that may suit a satellite. Satellites can also be classified according to their orbital planes (equatorial $0 / 90$ Incline), or even classified according to their orbital shape (circular or elliptical). The four types of satellites based on their orbital altitude and shape are as follow Geostationary Orbit (GEO) at an orbital altitude around $36,000 \mathrm{~km}$ over the earth's equator in a circular orbit. Medium Earth Orbit (MEO) at orbital altitudes between 10,000 and $12,000 \mathrm{~km}$ over the earth's equator in a circular orbit. Low Earth Orbit (LEO) at orbital altitudes between 750 and $1,500 \mathrm{~km}$ over the earth's equator in a circular orbit. Highly Elliptical Orbit (HEO) at apogee altitude around 35,000km over the earth's equator in an elliptical orbit [3, 65-68].

The distance between GEO satellites and earth's surface is nearly $\frac{1}{10}$ of the distance to the Moon, and that leads a single satellite covers $\frac{1}{3}$ of the earth apart from the Polar Regions. However, such a long distance requires extremely high transmission power, which would not be suitable for all types of mobile phones. Hence, designing GEO satellites involve a trade-off between higher transmission signal power and enormous onboard antennas to deal with narrow beams. The signal which takes approximately a quarter of a second for a round trip to and from a satellite because of the distance would lead to increase path loss between a satellite and ground antennas, and a short but noticeable propagation delay. This becomes a disadvantage in terms of voice and data communications. A GEO's low elevation angle for an earth latitude of more than $50^{\circ}$ often results in greater multipath and atmospheric path losses, in addition to shadow fading. A GEO has a life expectancy of 15 years, yet it would be impossible to carry out any repairs despite the global GEO usage stands at around $41 \%$, as can be seen in the study conducted in 2015 . The process of handover is not feasible with GEOs, as its visibility time with an earth station is almost 24 hours. Thus, neither the earth station nor the user terminals need to track the satellite, as it is clearly 
stationary on a fixed point to the earth. Moreover, the size of satellites in GEO orbit varies between 3 and 6 tones. This raises both the operational complexity and the cost of launching such a satellite to travel such a long distance. Many environmental and health organizations have systematically voiced their opposition to the launch of satellites which although it only lasts a few minutes to reach outside the earth's atmosphere, it, nevertheless, causes serious environmental damage due to gas emission, they argue [3, 65-69].

Nearly a dozen MEO satellites are needed to cover the entire globe. MEO satellites have a shorter lifetime than GEOs, around 8 years long, due to a variety of reasons. For instance, MEOs complete their orbit around the world every 2-8 hours, often de-orbiting within their positions, which in turn leads to higher power consumption than GEOs and indeed less lifetime. MEOs are closer to earth than GEOs which results in lower path losses and transmission delay than GEOs. However, the strength of the received signal could be affected, because of the range and elevation angle inconsistency. Further, MEO satellite needs to be part of a set of MEO satellites, in order to cover the entire globe, this is in contrast to a GEO satellite that can function stand alone as a network offering a wide regional coverage footprint. MEO satellites offer GPS services among others. As a result, the cost and complexity of ground antennas are much higher than that of GEO satellites, as they need to track a minimum number from the set of orbiting MEO satellites in order to provide the full range of GPS services for both stationary and mobile terminals. MEOs move asynchronously relative to the earth and combined that with average user movement on earth requires complex network architecture: such as handover process, ISL, Doppler shift, resource management, and routing issues. In order to reduce the network and HO complexity, an optimum multi-beam coverage mode has been suggested, which yet requires complex smart antennas and increased power consumption. Although MEOs orbit at a low altitude, they face the Van Allen belt's radiation exposure, which affects the on-board electronic components. Deployment of MEO satellites in a space segment, is also challenging, as it is time-consuming, due to the large number that needs to be deployed, as well as the resulting distributed network structure $[2,65-70]$.

LEOs cover a smaller area compared to GEO and MEO satellites. At such an altitude a constellation of satellites, not less than 50 , is required for continuous operation to cover the entire globe. That means more LEO satellites need to be deployed than GEO and MEO together. This leads to higher costs and operational and deployment complexity with more satellites on standby, more launches, and a more complicated TT\&C control system. Moreover, high gain antennas in the ground would not be sufficient to be frequently directed towards the LEO satellites, as the satellites complete an orbit around the globe between every 10 to 40 Minutes. LEOs experience lower signal propagation delays and free-space path loss than GEO and MEO satellites. Orbiting at an altitude of up to $1500 \mathrm{~km}$, LEO satellites experience other detrimental effects that subsequently shorten their life to about 7 years: de-orbiting, atmospheric drag, solar radiation pressure, and the Earth's gravitational field, which has a strong pull on LEO satellites. Additionally, LEO experience the Van Allen belt radiation exposure, which shortens considerably the life expectancy of on-board electronic equipment. Despite the broad range of applications, they support, LEOs move asynchronously relative to the earth and combined with average user movement on ground requires a more complex network architecture than that of the GEO and MEO satellites. HEO satellites are used primarily for spying, science photography of celestial bodies far out in space, with transmission when close to the earth. HEOs are not suitable for global coverage on their own as the transmission delays can be far greater than GEO satellites. HEOs are mainly used to cover the Polar Regions, e.g. Russian Molniya/Orbita [2, 65-70].

To sum up, there are several advantages with satellite communications in comparison with terrestrial, for instance, global coverage area, broadcast and multicast multimedia services, Internet services to users on trains, ships, and airships, scalable and reconfigurable for use on 
temporary geographical sites, mobile applications, or in case of emergency and disaster situations and as a last-mile solution, with unique LOS advantage. Technological advancement in industrial satellite systems is widely aimed at reducing their cost and size, increasing mission lifetime, and enhancing QoS. Therefore, satellite systems are not without challenges; for instance, propagation delay, handover complexity, high power consumption and cost, environmental issues with their high gas emissions during satellite launches, as well as signals have no regard for geographical or political boundaries, which in some cases might be a desirable feature but, in some cases, might not. In addition, there are several other important issues such as energy consumption, transmission delay, complexity and cost of (launching and tracking), attenuation, HO process, and a variety of environmental issues. Propagation signal delay (latency) describes the length of time that takes for the satellite to communicate with ground stations. Latency derives from several factors, most importantly, the huge distance between a satellite that needs to send a signal to a ground receiver. GEO satellites, which are located at around 36,000 km above ground, so 250 milliseconds exemplify this. The number is quite small, but it causes an echo over telephone connections and low QoS for TCP connectivity.

Moreover, for MEO, LEO satellites the signal delay is much less than that of GEOs. Satellites in MEO and LEO orbits are moving around the world to provide global coverage. De-orbiting within their positions, atmospheric drag, solar radiation pressure, and Earth's gravitational pull, often lead to a shorter satellite lifetime. The atmospheric features such as blockage, fading and shadowing due to the huge distances often raise dynamically-varying characteristics for the satellite channels. Thus, certain considerations like diversity, retransmission, adaptive modulation, link margins, and network coding need to be taken into account to obtain a more reliable channel. Moreover, Rain fade forces satellite systems to drop frequency usage over 30 $\mathrm{GHz}$ to the lower frequency of the $\mathrm{L}$ and $\mathrm{C}$ bands. Whilst higher frequency bands offer access to wider bandwidths, this makes a channel more vulnerable to signal degradation, as radio signals get affected by rain fade [3, 65-70].The higher frequency bands provide access to the wider bandwidths and are vulnerable to signal degradation, as radio signals get absorbed by atmospheric rain, snow or ice (rain fade). Hence, these frequency bands are more suitable for certain geographical regions, such as countries in Africa or Middle-east, which experience less annual rainfall than Europe or East Asia. Relevant research investigates how to utilize these higher frequency bands. The lower frequency bands, on the other hand, are gradually being used up. Satellites are undeniably expensive. From construction to balancing the trade-off between antenna size and signal power to launch into space to maintenance in an environment hostile to sustaining human life, the cost rises exponentially. Often the cost of carrying out major repairs is not costeffective unlike HAPs [3, 38, 65-70]. Table 3 below summarises the main challenges with satellite communications, as have been discussed above.

Table 3 Challenges with satellites communications

\begin{tabular}{|c|l|}
\hline Topic & \multicolumn{1}{c|}{ Challenges } \\
\hline \multirow{4}{*}{ Energy } & $\begin{array}{l}\text { GEOs require high levels of transmission power that is unsuitable for mobile } \\
\text { phones }\end{array}$ \\
\cline { 2 - 2 } & Environmental damage resulting from gas emissions during launch \\
\hline \multirow{2}{*}{$\begin{array}{c}\text { Coverage } \\
\text { Footprint }\end{array}$} & $\begin{array}{l}\text { De-orbiting is essential for MEO and LEO leading to high power consumption } \\
\text { and complex handover }\end{array}$ \\
\cline { 2 - 2 } $\begin{array}{l}\text { HEO Not suitable for global coverage by its own, transmission delay can be } \\
\text { greater than GEO satellites }\end{array}$ \\
\hline \multirow{2}{*}{$\begin{array}{c}\text { Propagation } \\
\text { model }\end{array}$} & $\begin{array}{l}\text { Considerable propagation delay (GEO, MEO) in compared to terrestrial and } \\
\text { Aerial platforms }\end{array}$ \\
\cline { 2 - 2 } QoS & Space path loss, due to the huge distance \\
\hline Bandwidth steadily being used up \\
\hline
\end{tabular}




\begin{tabular}{|c|l|}
\hline \multirow{5}{*}{ Reliability } & $\begin{array}{l}\text { Complex TTC control and HO processes with MEOs and LEOs compared to } \\
\text { GEOs }\end{array}$ \\
\hline \multirow{3}{*}{ Cost } & $\begin{array}{l}\text { De-orbiting, atmospheric dragging, solar radiation pressure, gravitational pull } \\
\text { shorten satellite lifetime (MEO,LEO) }\end{array}$ \\
\cline { 2 - 2 } & Van Allen belt radiation shortens MEO and LEO satellite lifetime \\
\cline { 2 - 2 } & $\begin{array}{l}\text { Maintenance whilst in orbit may not be humanly feasible or economically } \\
\text { impossible }\end{array}$ \\
\hline & $\begin{array}{l}\text { Operational complexity and cost of MEO and LEO ground antennas much } \\
\text { higher than GEO }\end{array}$ \\
\cline { 2 - 3 } & Operational complexity and cost of launch are high \\
\hline
\end{tabular}

\section{Open Chanllenges}

As have been mentioned, this paper is focused on terrestrial-aerial platforms- satellite wireless communications systems includes their characteristics and unravelling challenges. This section highlights open research issues that can be considered for further research work.

\subsection{Power Consumption}

In BSs power consumption and energy provision in remote areas are challenging, especially where more time is needed for renewable energy to be widely deployed. From aerial platforms side, station keeping or platform stability due to weather systems results in QoS degradation (e.g. handover process, complexity for optical inter-platform-link (IPL), which in turn requires increased power consumption to rectify. Further, power consumption has a negative correlation to its endurance time in space, which is again a mechanical challenge that is related to maximum communication and powering payloads. Satellites suffer high power consumption due to the huge distance, and deorbiting, which results in shorten satellites lifetime.

\subsection{Frequency band}

In terrestrial systems, lower frequency bands compare with space-based wireless systems, which leads to higher data volume demand due to the wide range of innovative applications and services. Where asaerial platforms facilitate high frequencies bands (e.g. $47 / 48 \mathrm{GHz}$ and 28 $\mathrm{GHz}$ ), yet more rain attenuation and scattering affect performance. Further, bandwidth in satellites are steadily being used up, besides high-frequency band or optical space communications suffer from the absorption and rain attenuation. For all wireless communication systems, advanced interference mitigation techniques are always needed.

\subsection{Handover}

In terrestrials and aerial platforms, handover and interferences management are quite complex due to small cell technology, and multi-tier networks, which aim to increase multiple spot beams over a coverage area to sustain frequency reuse. On the other hand, handover in satellites is existed in MEOs and LEOs due to the movements, but less complex than other systems due to beam forming large cells.

\subsection{Cost effeteness}

In the terrestrial system, the complexity of essential staged deployment especially in urban areas, and high-cost infrastructure to provide wireless communications for short-term large- scale events. Whereas in aerial platforms partial testing and trial abilities limit the completeness results to evaluate a complete system composed of several aerial platforms, which due to high implementation cost. Thus, deep business analysis is required to understand the market potential 
of aerial platforms compared to satellite and terrestrial networks. Satellite system shows high operational complexity of manufacturing, launching, and TTC control, besides the environmental damage resulting from gas emissions during launch.

\subsection{QOS}

QoS levels of the terrestrial system are affected by signal attenuation. In and Satellites, tailoring and adaptation of channel assignment and resource allocation resulting from either movement and/or distance are affected by applications with QoS requirements such as multimedia.

\subsection{Propagation conditions}

Limitation of coverage area in terrestrial systems is linked directly to certain issues, e.g. layout of covered area, transmission power, propagation conditions, and lack of LoS in metropolitan areas due to the number of obstacles that affect terrestrial cell coverage resulting shadowing and multipath. However, Satellites and aerial platforms have an advantage of more LoS. But the former suffers from the lack of studying and investigating various propagation models, where many recommendations are raised about the significance of that. The latter suffers from propagation delay, space path loss due to the huge distance.

Altitude and coverage, propagation and performance, link budget analysis, power supply constraints, deployment and maintenance challenges, reliability on special events or disaster relief, cost-effectiveness and environmental impact all these are parameters that will be compared and contrasted in the following Table 4 shows comprehensive comparison between the terrestrial, aerial platforms, and satellite systems based on the literature review that been highlighted throughout this paper. [1-73].

Table 4: Comprehensive Comparison between terrestrial, aerial platforms, and satellite systems

\begin{tabular}{|c|c|c|c|}
\hline Issue & Terrestrial & Aerial Platform & Satellite \\
\hline $\begin{array}{c}\text { Power } \\
\text { consumption }\end{array}$ & High & Low & Low \\
\hline Power supply & Electricity & $\begin{array}{l}\text { Fuel, propellers, Solar } \\
\text { panels }\end{array}$ & Solar panels \\
\hline $\begin{array}{l}\text { Altitude } \\
\text { above } \\
\text { ground }\end{array}$ & Up to $250 \mathrm{~m}$ & $0.1-20 \mathrm{~km}$ & 750-36000km \\
\hline Capacity & $\begin{array}{l}\text { Low, due to attenuation } \\
\text { by terrain and/or } \\
\text { obstacles }\end{array}$ & $\begin{array}{l}\text { High, due to low } \\
\text { altitude, so low } \\
\text { attenuation and delay }\end{array}$ & $\begin{array}{l}\text { Low in especially } \\
\text { GEOs, due to large } \\
\text { path loss by high } \\
\text { altitude }\end{array}$ \\
\hline $\begin{array}{l}\text { Frequency } \\
\text { band }\end{array}$ & Few GHz & $\begin{array}{c}1,2,4,6,12-18,27-40 \\
\mathrm{GHz}\end{array}$ & $\begin{array}{c}1,2,4,6,12-18,27-40 \\
\mathrm{GHz}\end{array}$ \\
\hline Coverage & Land and coastline & Land and sea & Land and sea \\
\hline $\begin{array}{c}\text { Geographical } \\
\text { coverage }\end{array}$ & Few km per BS & $\begin{array}{l}\text { Up to } 400 \mathrm{~km} \text { per } \\
\text { Platform }\end{array}$ & $\begin{array}{c}\text { GEO: Large regions } \\
\text { MEO/LEO: Global } \\
>500 \mathrm{~km}\end{array}$ \\
\hline $\begin{array}{l}\text { Propagation } \\
\text { delay }\end{array}$ & Varies & Very low & GEO/MEO: High \\
\hline Cell diameter & $100 \mathrm{~m}-2 \mathrm{~km}$ & $0.5-10 \mathrm{~km}$ & $50-500 \mathrm{~km}$ \\
\hline Lifetime & Long term & Up to 5 years & up to 15 years \\
\hline $\begin{array}{l}\text { Deployment } \\
\text { timing }\end{array}$ & In stages & $\begin{array}{l}\text { Minimum of one } \\
\text { platform/ground station }\end{array}$ & $\begin{array}{l}\text { MEO/LEO: In stages } \\
\text { GEO: } 1 \text { stand-alone }\end{array}$ \\
\hline Indoor & Substantial & Substantial & Complex \\
\hline
\end{tabular}


International Journal of Computer Networks \& Communications (IJCNC) Vol.11, No.6, November 2019

\begin{tabular}{|c|c|c|c|}
\hline reception & RF channel \\
quality & $\begin{array}{c}\text { Good signal quality } \\
\text { with appropriate } \\
\text { antenna placement, } \\
\text { Rayleigh fading }\end{array}$ & Free-space channel & $\begin{array}{c}\text { Free-space channel, } \\
\text { distance limits } \\
\text { spectrum efficiency, } \\
\text { Ricean fading, path } \\
\text { loss }\end{array}$ \\
\hline $\begin{array}{c}\text { HO } \\
\text { complexity }\end{array}$ & High & Low & Medium \\
\hline $\begin{array}{c}\text { Complexity } \\
\text { Shadowing } \\
\text { from terrains }\end{array}$ & $\begin{array}{c}\text { Operating in rural areas } \\
\text { needs additional } \\
\text { equipment }\end{array}$ & $\begin{array}{c}\text { Facing wind / Re- } \\
\text { fueling }\end{array}$ & $\begin{array}{c}\text { Complex MEOs and } \\
\text { LEOs movement }\end{array}$ \\
\hline $\begin{array}{c}\text { Elevation } \\
\text { angles }\end{array}$ & Low & $\begin{array}{c}\text { Problem only at low } \\
\text { elevation angles }\end{array}$ & $\begin{array}{c}\text { Problem only at low } \\
\text { elevation angles }\end{array}$ \\
\hline $\begin{array}{c}\text { Path loss } \\
\text { model }\end{array}$ & $\begin{array}{c}\text { Non-Free Space Loss } \\
\text { (NFSL) }\end{array}$ & $\begin{array}{c}\text { FSL and other } \\
\text { empirical models }\end{array}$ & High \\
\hline $\begin{array}{c}\text { Disaster } \\
\text { relief }\end{array}$ & Vulnerable to disasters & $\begin{array}{c}\text { Quick and Easy service } \\
\text { provision }\end{array}$ & FSL \\
\hline
\end{tabular}

\section{NETWORK ARCHITECTURE AND DISCUSSION}

There are many sites worldwide embrace short-term, large-scale high-density populated events such as sports activities, cultural activities, and religion events (e.g. pilgrimage), which need the immediate and movable wireless systems. Equally, it should meet the cost of temporary wireless communication infrastructure. Further, the reliability of telecommunication systems during emergency crises made the difference between life and death in respect of the response of the local authorities, where it is essential to have a large-scale and robust communication the network for broadcasting instructions to people, seeking rescue aid, as well as providing interdepartmental communications. Fig.2 shows network architecture of the terrestrial, aerial platforms (LAP, and HAP), and satellite systems. Each system provides different coverage that suite its altitude, and delivers the best performance possible of wireless communication services to short-term, large-scale (temporary) events. 


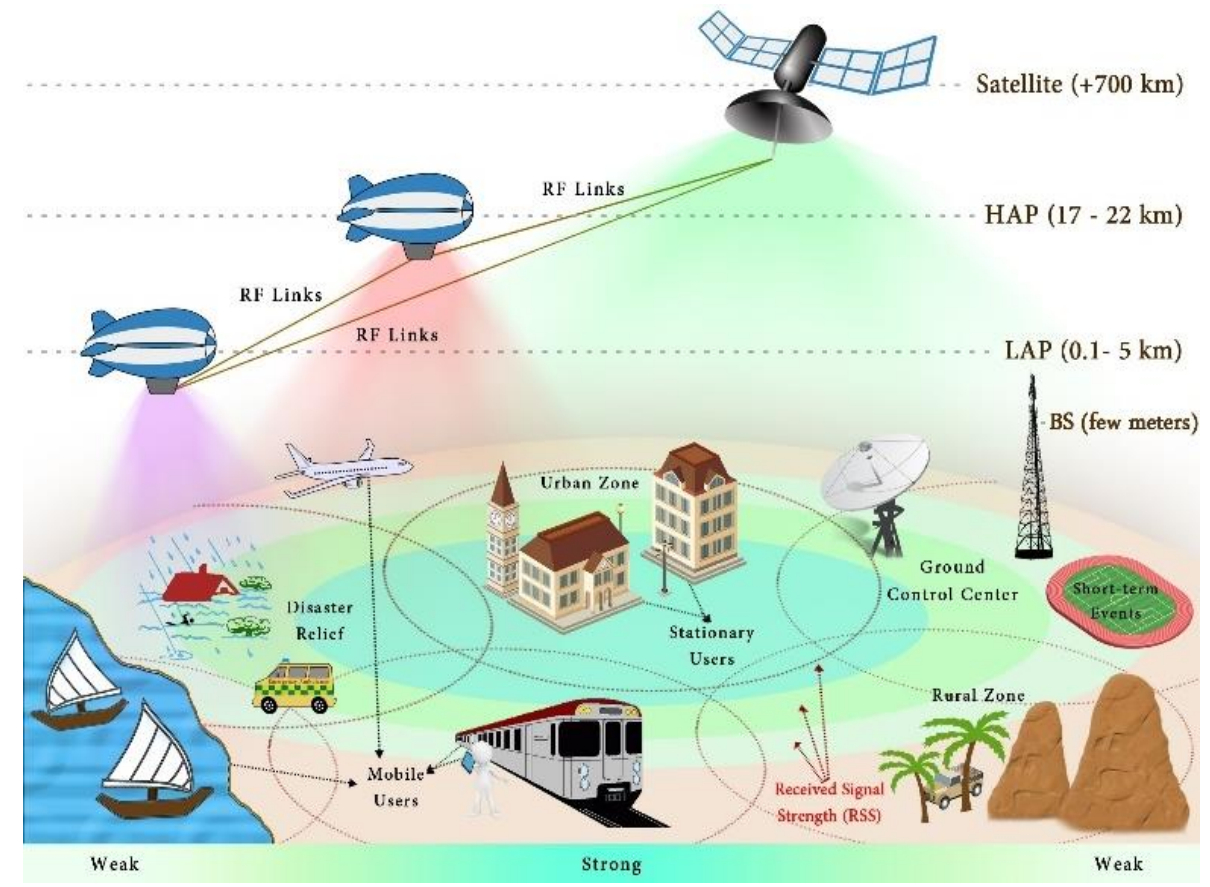

Fig.2: Proposed Network Architecture

\subsection{Implementation and Simulation Parameters}

Designing an efficient network and check its performance is a critical task, thus it is rational to consider a simulator. For this network, Optimized Network Engineering Tool (OPNET) Modeller is considered which can provide different levels of modelling depending on the necessities and requirements of simulation. The proposed model aims to develop several network scenarios to assess and analyse thenetwork performance of terrestrial, LAP, HAP, and satellites, respectively, with their communication WiMAX payload. Fig.3 shows the OPNET simulator of WiMAX network diagram with 10000 mobile nodes. Based on the above discussion and comparison, the selected wireless communication systems will be evaluated with respect to parameters includes:End-to-end delay, jitter, Mean Opinion Score (MOS), and Throughput. Evaluating these parameters can help in Ad hoc network planning, and assessing QoS requirements using freespace propagation model for all architecture Systems (terrestrial, LAP, HAP, and Satellite). TABLE 5 shows the simulation parameters that relate to antenna specifications, as well as OPNET simulator parameters. 


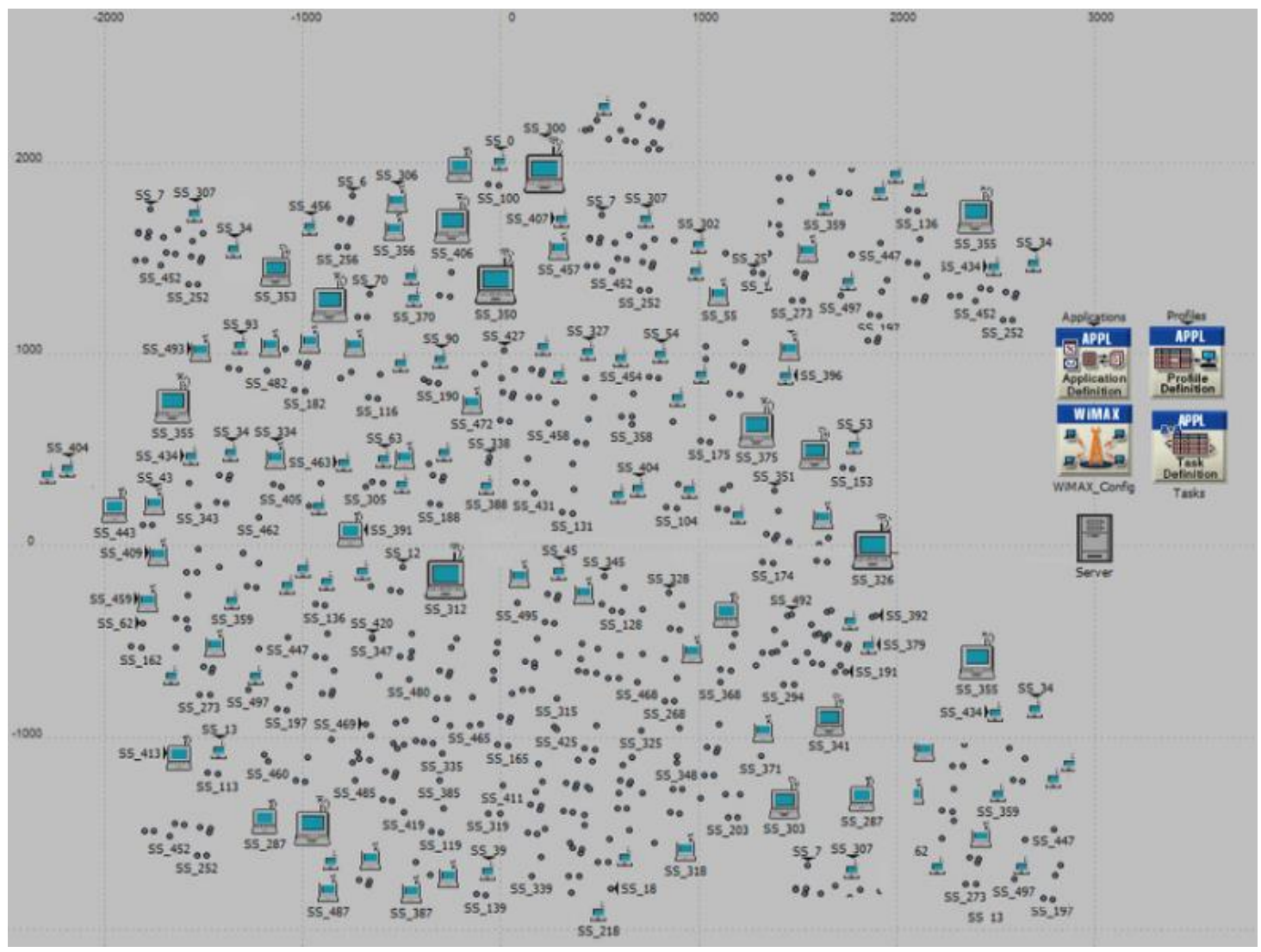

Fig.3: OPNET simulator of WiMAX network with mobile nodes

Table 5: Simulation Parameters

\begin{tabular}{|l|c|}
\hline \multicolumn{1}{|c|}{ Parameters } & Value \\
\hline Frequency band for Terrestrial, LAP/HAP $[\mathrm{GHz}]$ & $\mathbf{3 . 5}$ \\
\hline Frequency band for Satellite $[\mathrm{GHz}]$ & $\mathbf{3 . 7}$ \\
\hline Network size $\left[\mathrm{km}^{2}\right]$ & $\mathbf{1 5}$ \\
\hline Mobility model & $\mathbf{2 0}$ \\
\hline Bandwidth $(\mathrm{MHz})$ & TDD \\
\hline Duplex Technique & Adaptive \\
\hline Modulation Technique & Rayleigh Fading \\
\hline Fading Model & ITU Vehicular A \\
\hline Multipath Channel Model & $\mathbf{1 0 0 0}$ \\
\hline Simulation time $[$ Seconds] & $\mathbf{4 0}$ \\
\hline \multicolumn{1}{|c|}{ Transmitter side } & $\mathbf{1 7}$ \\
\hline Maximum Transmitter Power $[\mathrm{dBm}]$ & $\mathbf{6}$ \\
\hline Transmitter Antenna Gain $[\mathrm{dBi}]$ & $\mathbf{- 8 9}$ \\
\hline Diversity gain $[\mathrm{dBi}]$ & $\mathbf{3}$ \\
\hline Transmitter Rx Sensitivity $[\mathrm{dBm}]$ & $\mathbf{0 . 3}$ \\
\hline Interference margin loss $[\mathrm{dB}]$ & $\mathbf{6}$ \\
\hline Connector loss [dB] & $\mathbf{0 . 0 5}$ \\
\hline Fading margin $[\mathrm{dB}]$ & $\mathbf{5}$ \\
\hline Terrestrial Base Station altitude $[\mathrm{km}]$ & $\mathbf{2 0}$ \\
\hline LAP altitude [km] & \\
\hline HAP altitude $[\mathrm{km}]$ & \\
\hline
\end{tabular}


International Journal of Computer Networks \& Communications (IJCNC) Vol.11, No.6, November 2019

\begin{tabular}{|c|c|}
\hline Satellite altitude $[\mathrm{km}]$ & 800 \\
\hline \multicolumn{2}{|c|}{ Receiver side } \\
\hline Maximum Receiver Power [dBm] & 27 \\
\hline Receiver Antenna Gain [dBi] (stations) & 15 \\
\hline Receiver Antenna Gain [dBi] (handset) & 3 \\
\hline Diversity gain $[\mathrm{dBi}]$ & 3 \\
\hline Receiver Rx Sensitivity [dBm] & -91 \\
\hline Interference margin loss [dB] & 3 \\
\hline Connector loss $[\mathrm{dB}]$ & 0.1 \\
\hline Body loss [dB] & 0.1 \\
\hline
\end{tabular}

\subsection{Simulation Results and Discussion}

In this subsection, VoIP over mobile WiMAX network is analysed and discussed. Several simulation runs have been performed for each wireless system to measure delay, jitter, MOS, and throughput using the OPNET Modeller simulation tool, as following fig.5 to fig. 8 show. Evaluating these parameters can help in Ad hoc network planning, and assessing QoS requirements using free-space propagation model for all architecture Systems (terrestrial, LAP, HAP, and Satellite).

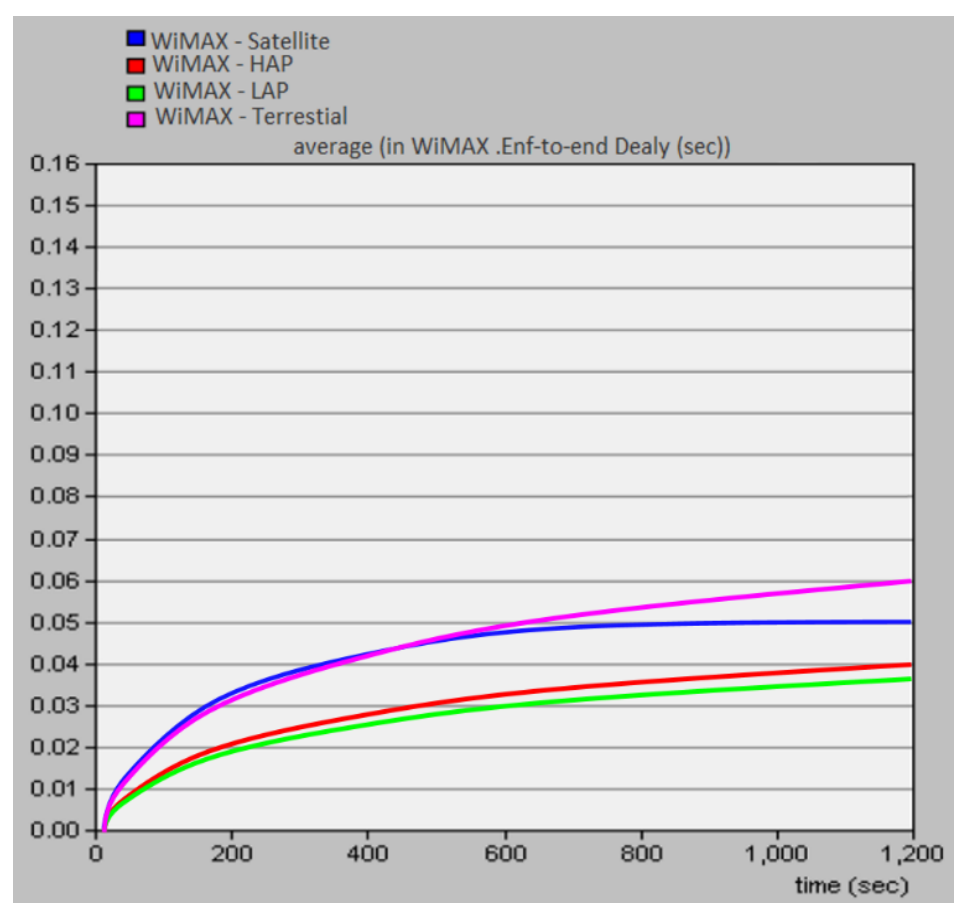

Fig.5: End to end delay using OPNET tool 
International Journal of Computer Networks \& Communications (IJCNC) Vol.11, No.6, November 2019

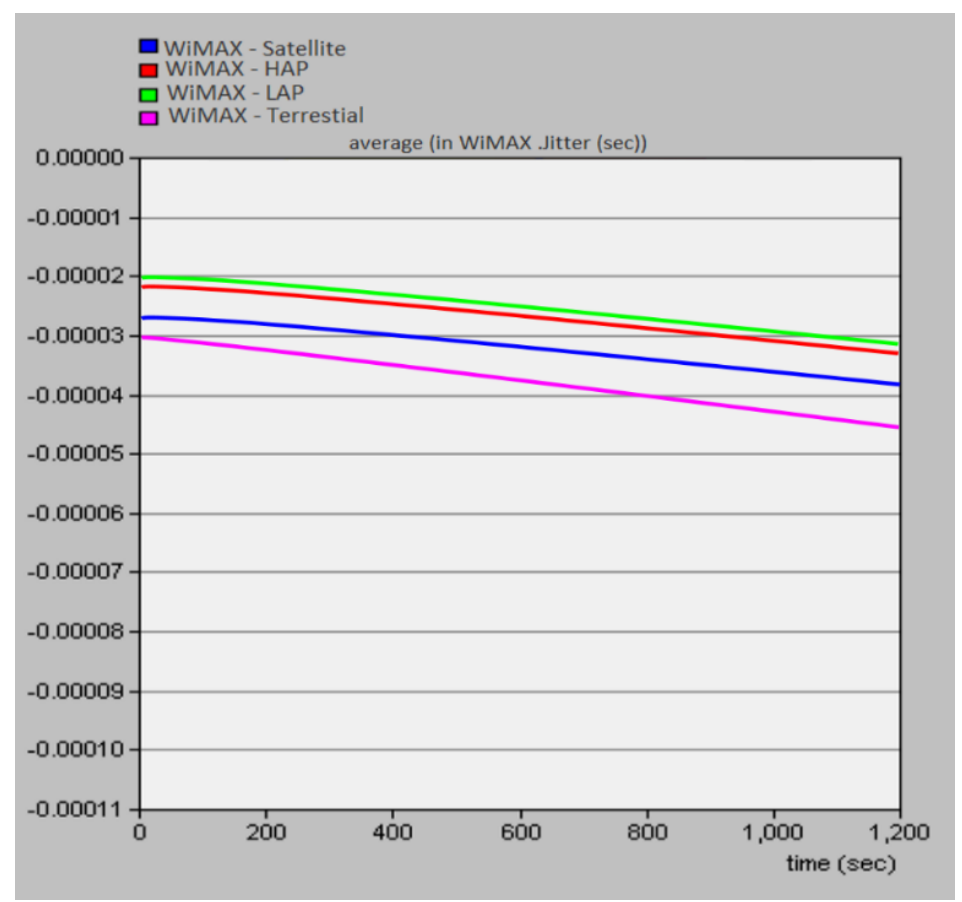

Fig.6: Jitter using OPNET tool

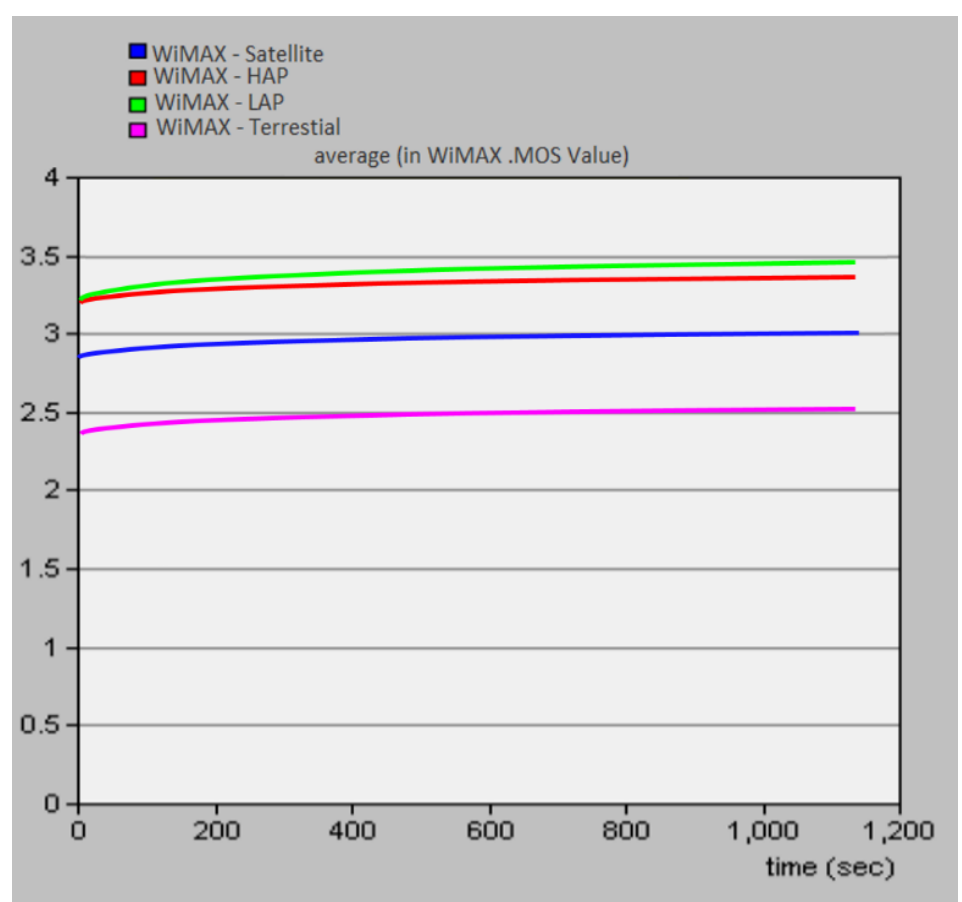

Fig.7: MOS Value using OPNET tool 


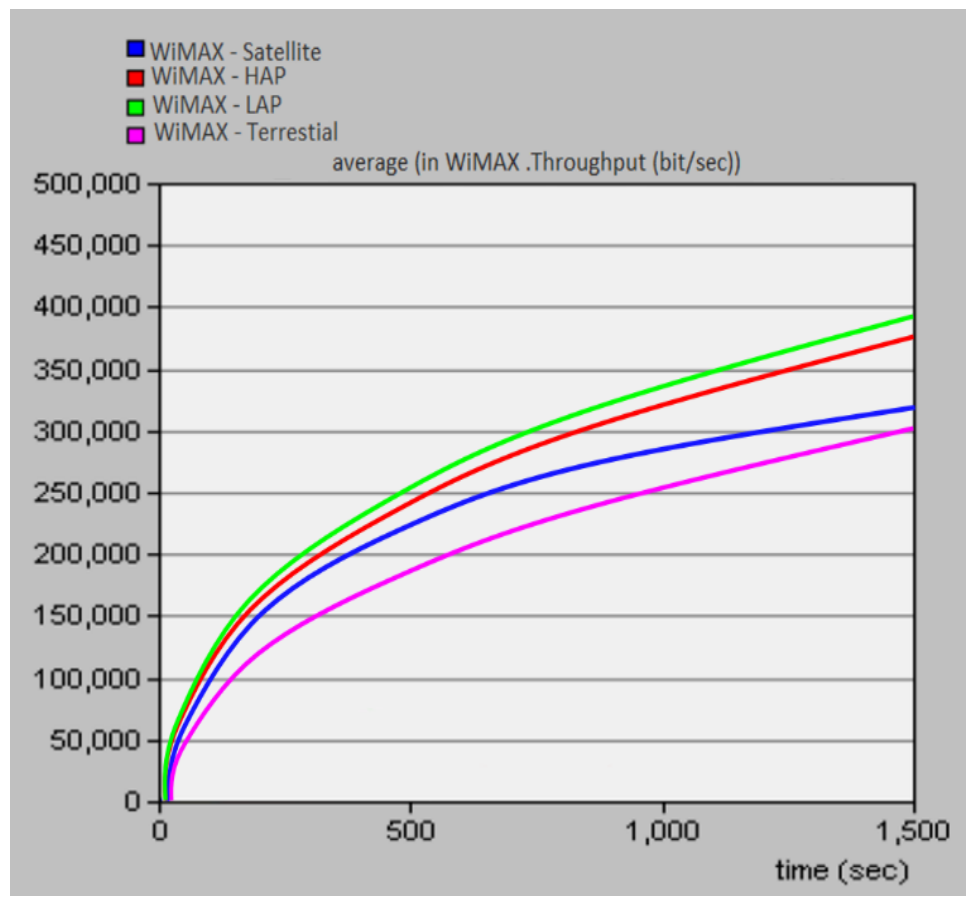

Fig.8: Throughput using OPNET tool

From figures5-8 that exported from OPNET Modeller simulator show the average performance of VoIP QoS in WiMAX networks for the four different scenarios (terrestrial, LAP, HAP, and Satellite). Fig.5 shows end to end delay which gradual increases for all systems. Terrestrial system shows the highest value of delay, whereas space-based systems especially LAP experience better performance due to short distance. Fig. 6 represents the jitter performance of the four wireless systems, which can be considered as the end-to-end delay variation between two consecutive packets. It is quite clear the average jitter values increase linearly with time. Again, the Terrestrial system shows the highest value, while LAP displays the lowest with a $40 \%$ difference. Fig.7 shows the MOS value which is a telecommunication performance indicator that measures the quality of voice and video, where often judged on a scale of 1 (bad) to 5 (excellent). All systems show reasonable MOS values, the however terrestrial system shows the lowest value, while LAP displays the best performance. Fig. 8 illustrates the throughput simulation results of the four systems, which represents the amount of the number of packets effectively transferred in a network. LAP system registers as the highest throughput, while terrestrial the lowest. Clearly, from the simulation results that space-based systems especially LAP experience better performance, while terrestrial is the lowest. There are many reasons for this, space-based systems have always better LoS connectivity; second, due to using frequency recues space-based systems can accommodate more users in their large footprint coverage; third, the terrestrial system sometimes suffers from multipath and shadowing issues. On the other hand, observing the comparison tables 1 to 4 it evident that space-based systems especially aerial platforms technology (HAP and LAP) has advantages over both terrestrial and satellite systems with fewer limitations. Therefore, to establish an ad hoc but robust wireless communication service for shortterm, large-scale high-density populated can be delivered by relaying on aerial platforms technology. This considers as an efficient and cost-effective solution for such events including emergency crises, where it is essential to have a large-scale and robust communication network for broadcasting instructions to people, seeking rescue aid, as well as providing interdepartmental communications. 


\section{CONClUSION AND FUTURE WORK}

This paper highlights a comprehensive study on terrestrial-aerial platforms (HAP/LAP)- satellite wireless communications systems, includes some of their characteristics and unravelling challenges with deep analysis in the literature. Then, VoIP QoS is analysed over mobile WiMAX networks using the OPNET Modeller simulation tool from a temporary events perspective for the selected wireless communications systems. Both comparative studies drawn from the literature review and simulation results emphasize that aerial platforms technology (HAP, and LAP) outperform terrestrial and satellite systems in many aspects, include rapid deployment, large coverage, low altitude with no significant delays or loss, providing line of sight connectivity, environmentally-friendly. Such technology can present a low-cost solution in response to shortterm large-scale events include emergency events. Aerial platforms clearly holds the promise to swiftly bridge the coverage gaps in such events with the best scenario possible. As future work, considering an optimized indoor-outdoor propagation model may help include and fine-tune environmental considerations.

\section{REFERENCES}

[1] M. Mozaffari, W. Saad, M. Bennis, Y. Nam And M. Debbah, "A Tutorial On Uavs For Wireless Networks: Applications, Challenges, And Open Problems", Ieee Communications Surveys \& Tutorials, Pp. 1-1, 2019.

[2] K. Du And M. Swamy, Wireless Communication Systems. Cambridge, Uk: Cambridge University Press, 2018.

[3] F. A. Almalki, M. C. Angelides, "Considering Near Space Platforms To Close The Coverage Gap In Wireless Communications; The Case Of The Kingdom Of Saudi Arabia," Ftc 2016 San Francisco Future Technologies Conference, 2016, Pp.224 - 230.

[4] R. Frenkiel And M. Schwartz, 'Creating Cellular: A History Of The Amps Project (1971-1983) History Of Communications', Ieee Communications Magazine, Vol. 48, No. 9, Pp. 14-24, 2015.

[5] Mobile Phones, Tv, Internet And Home Phone Service | Bell Canada', [Online]. Available: Http://Www.Bell.Ca/. [Accessed: 22- Feb- 2019].

[6] W. Yu, H. Xu, J. Nguyen, E. Blasch, A. Hematian And W. Gao, "Survey Of Public Safety Communications: User-Side And Network-Side Solutions And Future Directions", Ieee Access, Vol. 6, No. 1, Pp. 70397-70425, 2018.

[7] S. H. Alsamhi, M. S. Ansari, O. Ma, F. Almalki, And S. K. Gupta, "Tethered Balloon Technology In Design Solutions For Rescue And Relief Team Emergency Communication Services," Disaster Medicine And Public Health Preparedness, Pp. 1-8, May 2018.

[8] F. A. Almalki, M. C. Angelides, "Empirical Evolution Of A Propagation Model For Low Altitude Platforms," Ieeecomputing Conference 2017, 2017, Pp.1297-1304.

[9] Rangan, T. S. Rappaport, And E. Erkip, 'Millimeter-Wave Cellular Wireless Networks: Potentials And Challenges', Proceedings Of The Ieee, Vol. 102, No. 3, Pp. 366-385, Jan. 2014.

[10] S. Dawoud, A. Uzun, S. Gondor, And A. Kupper, "Optimizing The Power Consumption Of Mobile Networks Based On Traffic Prediction," Ieee 38th Annu. Comput. Softw. Appl. Conf., 2014, Pp. 279-288.

[11] U. B. Antonio Capone Ilario Filippini Bernd Gloss, "Rethinking Cellular System Architecture For Breaking Current Energy Efficiency Limits," Sustain. Ieee Internet Ict Sustain. (Sustainit), 2012, Pp.1-5.

[12] S. Chen And J. Zhao, 'The Requirements, Challenges, And Technologies For 5g Of Terrestrial Mobile Telecommunication', Ieee Communications Magazine, Vol. 52, No. 5, Pp. 36-43, Jan. 2014.

[13] J. Gozalvez And B. Coll-Perales, 'Experimental Evaluation Of Multihop Cellular Networks Using Mobile Relays', Ieee Communications Magazine, Vol. 51, No. 7, Pp. 122-129, Jan. 2013.

[14] A. A. Ekram Hossain, Mehdi Rasti, Hina Tabassum, "Evolution Toward 5g Multi -Tier Cellular Wireless Networks: An Interference Management Perspective," Ieee Wirel. Commun., Pp. 118-127, 2014. 
[15] M. Di Renzo, H. Haas, A. Ghrayeb, S. Sugiura, And L. Hanzo, 'Spatial Modulation For Generalized Mimo: Challenges, Opportunities, And Implementation', Proceedings Of The Ieee, Vol. 102, No. 1, Pp. 56-103, Jan. 2014.

[16] L. Wei, R. Hu, Y. Qian, And G. Wu, 'Enable Device-To-Device Communications Underlaying Cellular Networks: Challenges And Research Aspects', Ieee Communications Magazine, Vol. 52, No. 6, Pp. 90-96, Jan. 2014.

[17] F. Ghavimi And H.-H. Chen, "M2m Communications In 3gpp Lte/Lte-A Networks: Architectures, Service Requirements, Challenges And Applications," Ieee Commun. Surv. Tutorials, Vol. 17, No. 12, Pp. 1-1, 2014.

[18] T. Han And N. Ansari, 'Powering Mobile Networks With Green Energy', Ieee Wireless Communications, Vol. 21, No. 1, Pp. 90-96, Jan. 2014.

[19] M. Bennis And M. Latva-Aho With Carlos H. M. De Lima, 'Modeling And Analysis Of Handover Failure Probability In Small Cell Networks', Ieee Conference On Computer Communications Workshops, 2014, Pp.736 - 741.

[20] J. Cole, F. A. Almalki, And P. R. Young, "Chipless Rf Liquid Sensor," Ieee International Microwave And Rf Conference (Imarc), 2015, Pp. 243 - 245.

[21] R. Razavi, D. Lopez-Perez, And H. Claussen, "Neighbour Cell List Management In Wireless Heterogeneous Networks," 2013 Ieee Wireless Communications And Networking Conference (Wcnc): Networks, 2013, Pp. 1220-1225.

[22] Y. Zhuang, S. Zhao, And X. Zhu, 'A New Handover Mechanism For Femtocell-To-Femtocell', International Conference On Wireless Communications And Signal Processing (Wcsp), 2012, Pp.1-4.

[23] M. Xia And S. Aissa, 'Underlay Cooperative Of Relaying In Cellular Networks: Performance And Challenges', Ieee Communications Magazine, Vol. 51, No. 12, Pp. 170-176, Jan. 2013.

[24] J. Cao, Maode, H. Li, Y. Zhang, And Z. Luo, 'A Survey On Security Aspects For Lte And Lte-A Networks', Ieee Communications Surveys \& Tutorials, Vol. 16, No. 1, Pp. 283-302, Jan. 2014.

[25] G. Hu, A. Huang, R. He, B. Ai, And Z. Chen, 'Theory Analysis Of The Handover Challenge In Express Train Access Networks (Etan)', China Communications, Vol. 11, No. 7, Pp. 92-98, Jan. 2014.

[26] G. Sharma, 'Performance Evaluation Of Wireless Multipath/Shadowed G-Distributed Channel', Journal Of Engineering And Technology Research, Vol. 5, No. 5, Pp. 139-148, Jan. 2013.

[27] Y.-H. Wang, G.-R. Huang, And Y.-C. Tung, 'A Handover Prediction Mechanism Based On Lte-A Ue History Information', Ieee Conference On Computer, Information And Telecommunication Systems, 2014, Pp. 167 - 172.

[28] J. Xu, Y. Zhao, And X. Zhu, 'Mobility Model Based Handover Algorithm In Lte-Advanced', Ieee10th International Conference On Natural Computation, 2014, Pp. 230 - 234.

[29] U. Dampage And C. B. Wavegedara, 'A Low-Latency And Energy Efficient Forward Handover Scheme For Lte-Femtocell Networks', Ieee 8th International Conference On Industrial And Information Systems, 2013, Pp. 53 - 58.

[30] A. Ahmed, L. M. Boulahia, And D. Gaiti, 'Enabling Vertical Handover Decisions In Heterogeneous Wireless Networks: A State-Of-The-Art And A Classification', Ieee Communications Surveys \& Tutorials, Vol. 16, No. 2, Pp. 776-811, Jan. 2014.

[31] G. N. Kamga, K. B. Fredj, And S. Aissa, 'Multihop Cognitive Relaying Over Composite Multipath/Shadowing Channels', Ieee Transactions On Vehicular Technology, Pp. 1-5, Jan. 2014.

[32] P. S. Bithas And T. Rontogiannis, 'Mobile Communication Systems In The Presence Of Fading/Shadowing, Noise And Interference', Ieee Transactions On Communications, Pp. 1-13, Jan. 2015.

[33] A. Laourine, M.-S. Alouini, S. Affes, And A. Stephenne, 'On The Performance Analysis Of Composite Multipath /Shadowing Channels Using The G-Distribution', Ieee Conference On Communications, 2008, Pp. $1162-1170$.

[34] L. C. Wang And S. Rangapillai, “A Survey On Green 5g Cellular Networks,” Ieeeinternational Conference On Signal Processing And Communications (Spcom), 2012, Pp.1-5.

[35] P. Nema, 'Nobel Approach Of Power Feeding For Cellular Mobile Telephony Base Station Site: Hybrid Energy System', International Journal Of Energy And Power Engineering, Vol. 3, No. 6, Pp. 7-14, Nov. 2014.

[36] S. Khan And J. L. Mauri, Security For Multihop Wireless Networks. United States: Crc Press Inc, 2014. 
[37] International Telecommunication Union (Itu), 'Utilization Of Telecommunications/Icts For Disaster Preparedness, Mitigation And Response', 2014. [Online]. Available: Http://Www.Itu.Int/Dms_Pub/Itu-D/Opb/Stg/D-Stg-Sg02.22.1-2014-Pdf-E.Pdf. [Accessed: 28- Feb2015].

[38] A. K. Maini And V. Agrawal, Satellite Technology Principles And Applications. Third Edition. United Kingdom: Wiley, John \& Sons, Incorporated, 2014.

[39] D. Grace And M. Mohorcic, Broadband Communications Via High-Altitude Platforms. United Kingdom: Wiley-Blackwell (An Imprint Of John Wiley \& Sons Ltd), 2010.

[40] R. Nuwer, 'The Last Places On Earth Without The Internet', Bbc, Nov. 2014. [Online]. Available: Http://Www.Bbc.Com/Future/Story/20140214-The-Last-Places-Without-Internet. [Accessed: 28Mar-2015].

[41] 'Itu', International Telecommunication Union. [Online]. Available: Http://Www.Itu.Int/Newsarchive/Press/Wrc97/Skystation.Html. [Accessed: 27-Jan-2015].

[42] A. G. Flattie, 'Integrated Satellite- Aps-Terrestrial System For Umts And Lte Network', 2nd International Conference On Emerging Trends In Engineering And Technology (Icetet'2014), 2014, Pp.53-59.

[43] S. Hadiwardoyo, C. Calafate, J. Cano, Y. Ji, E. Hernandez-Orallo And P. Manzoni, "3d Simulation Modeling Of Uav-To-Car Communications", Ieee Access, Vol. 7, Pp. 8808-8823, 2019.

[44] S. Alsamhi, O. Ma, M. Ansari And F. Almalki, "Survey On Collaborative Smart Drones And Internet Of Things For Improving Smartness Of Smart Cities", Ieee Access, Pp. 1-29, 2019.

[45] S. A. Khaleefa, S. H. Alsamhi, And N. S. Rajput, 'Tethered Balloon Technology For Telecommunication, Coverage And Path Loss', Ieee Students' Conference On Electrical, Electronics And Computer Science, 2014, Pp.1-4.

[46] F. A. Almalki, M. C. Angelides, "Evolution Of An Optimal Propagation Model For The Last Mile With Low Altitude Platforms Using Machine Learning", Elsevier Computer Communications Journal, Vol. 142-143, Pp. 9-33, May 2019

[47] A. Al-Hourani, S. Kandeepan, And S. Lardner, 'Optimal Lap Altitude For Maximum Coverage', Ieee Wireless Communications Letters, Vol. 3, No. 6, Pp. 569-572, Dec. 2014.

[48] I. Dalmasso, I. Galletti, R. Giuliano, F. Mazzenga, "Wimax Networks For Emergency Management Based On Uavs," Ieee First Aess European Conference On Satellite Telecommunications (Estel), 2012, Pp.1-6.

[49] M. S. Aljumaily, "Routing Protocols Performance In Mobile Ad-Hoc Networks Using Millimeter Wave", International Journal Of Computer Networks \& Communications, Vol. 10, No. 4, Pp. 23-36, 2018.

[50] K. Gomez, A. Hourani, L. Goratti, R. Riggio, S. Kandeepan, I. Bucaille, "Capacity Evaluation Of Aerial Lte Base-Stations For Public Safety Communications," European Conference On Networks And Communications, 2015, Pp. 133-138.

[51] W. Khawaja, I. Guvenc, D. Matolak, U. C. Fiebig, And N. Schneckenberger, "A Survey Of Air-ToGround Propagation Channel Modeling For Unmanned Aerial Vehicles,'Electrical Engineering And Systems, Vol. 1801, No. 016, Pp.1-25, 2018.

[52] L. L. Hanzo, Mimo-Ofdm For Lte, Wi-Fi, And Wimax: Coherent Versus Non-Coherent And Cooperative Turbo-Transceivers. United States: John Wiley \& Sons, 2011.

[53] W. Feng, J. Wang, Y. Chen, X. Wang, N. Ge And J. Lu, "Uav-Aided Mimo Communications For 5g Internet Of Things", Ieee Internet Of Things Journal, Vol.1, No.1, Pp. 1-10, 2018.

[54] F. A. Almalki, M. C. Angelides, "Deployment Of An Aerial Platform System For Rapid Restoration Of Communications Links After A Disaster: A Machine Learning Approach”, Springer Computing Journal, Forthcoming.

[55] S. Alsamhi, O. Ma, M. Ansari And S. Gupta, "Collaboration Of Drone And Internet Of Public Safety Things In Smart Cities: An Overview Of Qos And Network Performance Optimization", Drones, Vol. 3, No. 1, P. 13, 2019.

[56] S. Aljahdali, 'Enhancing The Capacity Of Stratospheric Cellular Networks Using Adaptive Array Techniques', International Journal Of Computer Network And Information Security, Vol. 5, No. 6, Pp. 1-10, 2013.

[57] U. R. Mori, P. Chandarana, G. Gajjar, And S. Dasi, "Performance Comparison Of Different Modulation Schemes In Advanced Technologies Wimax And Lte," Ieee International Advance Computing Conference, 2015, Pp. 286 - 289. 
[58] I. Aldmour, "Lte And Wimax: Comparison And Future Perspective," Communications And Network, Vol. 05, No. 04, Pp. 360-368, 2013.

[59] H. Hariyanto, And A. K. Widiawan, 'Emergency Broadband Access Network Using Low Altitude Platform', International Conference On Instrumentation, Communication, Information Technology, And Biomedical Engineering, 2009, Pp.1-6.

[60] F. Almalki, M. Angelides, "Propagation Modelling And Performance Assessment Of Aerial Platforms Deployed During Emergencies," 12th Ieee International Conference For Internet Technology And Secured Transactions, 2017, Pp.238-243.

[61] M. A. Rahman, 'Enabling Drone Communications With Wimax Technology', Ieee 5th International Conference On Information, Intelligence, Systems And Applications, 2014, Pp. 323 - 328.

[62] Q. Zhang, M. Jiang, Z. Feng, W. Li, W. Zhang And M. Pan, "Iot Enabled Uav: Network Architecture And Routing Algorithm", Ieee Internet Of Things Journal, Pp. 1-1, 2019.

[63] Iskandar And A. Abubaker, "Co-Channel Interference Mitigation Technique For Mobile Wimax Downlink System Deployed Via Stratospheric Platform," Ieee 8th International Conference On Telecommunication Systems Services And Applications (Tssa), 2014, Pp.1-5.

[64] P. Bilaye, V. Gawande, U. Desai, A. Raina, And R. Pant, 'Low Cost Wireless Internet Access For Rural Areas Using Tethered Aerostats', Ieee Third International Conference On Industrial And Information Systems, 2008, Pp.1-5.

[65] G. S. Rao, Mobile Cellular Communication. India: Pearson Education India, 2013.

[66] J. N. Pelton, S. Madry, S. Camacho-Lara, And Editors., Handbook Of Satellite Applications: 2013. United States: Springer-Verlag New York Inc., 2013.

[67] C. Saunders, 'The Role Of Small Satellites In Military Communications', Iet Seminar On Military Satellite Communications, 2013, Pp.1-13.

[68] B. Li, Z. Fei And Y. Zhang, "Uav Communications For 5g And Beyond: Recent Advances And Future Trends", Ieee Internet Of Things Journal, Vol. 6, No. 2, Pp. 2241-2263, 2019.

[69] M. Sadek And S. Aissa, 'Personal Satellite Communication: Technologies And Challenges', Ieee Wireless Communications, Vol. 19, No. 6, Pp. 28-35, 2012.

[70] B. G. Evans, 'The Role Of Satellites In 5g', Ieee 7th Advanced Satellite Multimedia Systems Conference And The 13th Signal Processing For Space Communications Workshop (Asms/Spsc), 2014, Pp.197 - 202.

[71] J. Liu, Y. Shi, Z. Fadlullah And N. Kato, "Space-Air-Ground Integrated Network: A Survey", Ieee Communications Surveys \& Tutorials, Vol. 20, No. 4, Pp. 2714-2741, 2018.

[72] S. Alsamhi And N. Rajput, "An Intelligent Hap For Broadband Wireless Communications: Developments, Qos And Applications", International Journal Of Electronics And Electrical Engineering, Vol. 3, No. 2, Pp. 134-143, 2014.

[73] L. Zhao, H. Zhang, F. Liu, K. Yang And L. Cong, "Joint Time-Frequency-Power Resource Allocation For Low-Medium-Altitude Platforms-Based Wimax Networks", Iet Communications, Vol. 5, No. 7, Pp. 967-974, 2011.

[74] C. Manikandan, P. Neelamegam, R. Kumar, V. Babu And S. Satwikkommi, "Design Of Secure And Reliable Mu-Mimo Transceiver System For Vehicular Networks", International Journal Of Computer Networks \& Communications, Vol. 11, No. 02, Pp. 15-32, 2019. Available: 10.5121/Ijcnc.2019.11202.

\section{AUTHORS}

Dr Faris A. Almalki is an assistant professor in wireless communications and satellites in Computer Engineering Department at Taif University. He is a PostDoctoral Researcher in the Department of Electronics and Computer Engineering at Brunel University London. He holds a BSc in Computer Engineering from Taif University, an MSc in Broadband and Mobile Communication Networks from Kent University and a $\mathrm{PhD}$. in Wireless Communication Networks from Brunel University London. He is a Member of the IEEE Communication Society. His research interests include Low- and High-

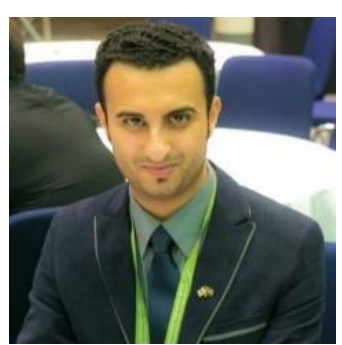
Altitude Platforms and their application in Ad hoc wireless networks. 